\title{
Estructura organizativa para la optimización de las investigaciones sociales de la radio y de la televisión en Santiago de Cuba
}

\author{
Mercedes Duvergel ISAAC ${ }^{1}$ \\ Ruthminy Daniella García RAMOS ${ }^{2}$
}

\begin{abstract}
Resumen:
El presente estudio propone desde una perspectiva cualitativa, la modelación de una estructura organizativa en función de la optimización del trabajo del sistema de investigaciones sociales para el sistema de la radio y la televisión en Santiago de Cuba. Se plantea en primera instancia la caracterización de este sistema y posteriormente el diseño de un equipo de investigación que se encargue de tales fines. Este estudio, de carácter explicativo, permite analizar las relaciones fáticas existentes en el Sistema de Investigaciones Sociales en los medios de comunicación, su composición, funcionamiento y el efecto que tiene en el desempeño y cumplimiento del objeto social de los medios, lo que permite crear una estructura dirigida a la optimización de dicho funcionamiento.

Palabras clave: Investigaciones sociales. Estructura Organizativa. Optimización.

\section{Estrutura organizativa para a otimização das investigações sociais do rádio e da televisão em Santiago de Cuba}

\section{Resumo:}

O presente estudo propõe, a partir de uma perspectiva qualitativa, a modelação de uma estrutura organizativa em função da otimização do trabalho do sistema de investigações sociais para o sistema de rádio e televisão em Santiago de Cuba. Expõe-se em primeira instância a caracterização desse sistema e posteriormente o desenho de uma equipe de investigação que se encarregue de tais fins. Este estudo, de caráter explicativo, permite analisar as relações fáticas existentes no Sistema de Investigações Sociais nos meios de comunicação, sua composição, funcionamento e o efeito que tem no desempenho e cumprimento do objeto social dos meios, o que permite criar uma estrutura dirigida à otimização de dito funcionamento.

Palavras-chave:

Investigações sociais. Estrutura Organizativas. Otimização.

\section{It structures organizational for the optimization of the social investigations of the radio and the television in Santiago from Cuba}

\begin{abstract}
:
The present studies "Social Investigations in the half mass: utopia or reality", it proposes from a qualitative perspective, the modulation of an organizational structure in function of the optimization of the work of the system of social investigations of the ICRT in Santiago from Cuba. It thinks about in first instance the characterization of this system and later on the design of a team of investigations that takes charge of such ends. The social investigations constitute of vital importance for the establishment of more narrow relationships between the media and their public, element that offers bigger present time to the study that here intends.

Keywords:

Social investigations. it Structures Organizational. Optimization.

\section{INTRODUCCIÓN}

\footnotetext{
${ }^{1}$ Lic. Periodismo. Máster en Ciencia de la Comunicación. Profesora Tiitular Universidad de Oriente, Cuba. Correo electrónico: merci@uo.edu.cu.

${ }^{2}$ Lic. Periodismo. Emisora CMKW Radio Mambí, Cuba. Correo electrónico: ruty@rmmabi.icrt.cu
} 
Las investigaciones sociales son de vital importancia para el establecimiento de relaciones más estrechas entre los medios de comunicación y su público, elemento que brinda mayor actualidad al estudio que aquí se propone, partiendo de que la comunicación es un proceso devenido en todo un campo investigativo, entenderla como tal es hoy una necesidad, si se quiere desentrañar los factores que se gestan al interior de su estructura.

Los medios de comunicación, si bien surgen para informar, educar, entretener; deben por sobre todas las cosas, ser una representación de la sociedad; responder a gustos y particularidades. De ahí que la interrogante ¿son en verdad los medios el reflejo de su público? sea una de las más aludidas, cuando de medios de comunicación se trata, por lo que se hace necesario la medición y caracterización de las audiencias; conocer preferencias, intereses y hábitos de vida, y de esta forma incluir la opinión del público en el proceso de planificación mediática, lo que formaría parte de una de las recetas más eficaces para el éxito de los mass media.

Sobre los años 80 con la ruptura de los grandes paradigmas comunicacionales, las investigaciones en América Latina dieron un giro hacia otra de las aristas del proceso comunicativo en la que hasta el momento no se habían centrado los estudios: el receptor. Se comprende entonces que los mensajes están expuestos a un proceso de negociación, cuestionamiento y confrontación por parte del destinatario, cuya lectura se encontraba mediada por la historia personal y el contexto económico, político-social en el que estaba ubicado.

La comprensión de este fenómeno se ha definido desde tres aristas fundamentales: emisor, mensaje y receptor. En un principio, se tenía la certeza de que lo más importante en el proceso comunicativo era el papel que desempeñaba el emisor y/o el mensaje; se necesitaron varias décadas para darse cuenta de que era necesario darle a la audiencia el rol que le correspondía.

Estos estudios conforman en la actualidad la premisa fundamental para el funcionamiento de los Medios de Comunicación, por lo que se han creado estructuras que permitan consolidar el desarrollo de estas investigaciones.

A nivel mundial existen instituciones dedicadas a la investigación mediática, en el caso de Cuba se ha de tener en cuenta que el sistema de medios posee características particularmente diferentes con respecto al resto del mundo, lo que a su vez no implica que en la isla no se potencie el estudio de los públicos, como vía de retroalimentación. 
En la Primera Conferencia Nacional del Partido Comunista de Cuba (2012), se plantea como una necesidad el garantizar que los medios de comunicación masiva se apoyen en criterios y estudios científicos, sean una plataforma eficaz de expresión para la cultura y el debate y ofrezcan caminos al conocimiento, al análisis y al ejercicio permanente de la opinión.

En investigaciones precedentes se ha estudiado el tema (DELGADO, 2013), dirigiendo la mirada a dicho sistema, de obligatorio énfasis para el análisis de la relación medio-receptor. Entre las principales deficiencias señaladas se destaca que este mecanismo de investigación en ocasiones no cuenta con un personal preparado para la adecuada realización de los estudios de audiencia, pues carecen de los instrumentos teóricos para tales fines.

Son estos los aspectos tenidos en cuenta en el presente trabajo que propone como problema de investigación la necesidad de crear una estructura organizativa en función de optimizar el trabajo del Sistema de Investigaciones Sociales de la Radio y la Televisión en Santiago de Cuba.

Es objetivo general de este estudio: modelar una estructura organizativa en función de la optimización del trabajo del Sistema de Investigaciones Sociales del Instituto Cubano de Radio y Televisión en Santiago de Cuba, a partir de su caracterización, determinando los factores que inciden en la organización del trabajo en estas estructuras de investigación, además de identificar las potencialidades de diversos perfiles profesionales que puedan integrar esta estructura organizativa, para un eficiente desarrollo de investigaciones sociales transdisciplinares.

La experiencia acumulada en procesos de optimización en los medios de comunicación, y los estudios científicos que se realizan al respecto en Cuba, dotan de información aprovechable para los fines de nuestra investigación. Este estúdio, de carácter explicativo, permite analizar explícitamente las relaciones fáticas existentes en el Sistema de Investigaciones Sociales en la radio y la televisión, su composición, funcionamiento y el efecto que tiene en el desempeño y cumplimiento del objeto social de los medios, lo que permite crear una estructura dirigida a la optimización de dicho funcionamiento.

Con un carácter comunicológico, este estudio se declara como Investigación Acción, desde un paradigma hermenéutico, con una perspectiva cualitativa, además de realizar la búsqueda e interpretación del fenómeno de acuerdo con los significados que 
tienen para las personas implicadas.

La investigação: sobre y desde los medios de comunicación"...

Las investigaciones son el proceso consciente mediante el cual pretendemos revelar, averiguar o descubrir algo; desde la ciencia se analiza como un procedimiento reflexivo, crítico y constante que tiene como fin explorar e interpretar fenómenos, en un determinado segmento de la realidad.

La investigación científica (SAMPIERI et al, 2006: XXXIX) se concibe como un conjunto de procesos sistemáticos y empíricos que se aplican al estudio de un fenómeno; es dinámica, cambiante y evolutiva (...) puede cumplir dos propósitos fundamentales a) producir conocimientos y teorías (investigación básica) y b) resolver problemas prácticos (investigación aplicada) (...) la investigación es la herramienta para conocer lo que nos rodea y su carácter universal

El profesor brasileño Rogério Christofoletti (2006), en su publicación "Observatorio de Medios: un caso brasileño", plantea que la emergencia de iniciativas para la crítica y análisis de los medios tiene sus inicios en el surgimiento de "media watchers" en los Estados Unidos, Europa y en actividades ya consolidadas en el resto del mundo - entre ellos Australia y Japón -, lo que aportó beneficios no solo en el sector empresarial sino a los profesionales que se desempeñan en estos medios y al público en general.

El sociólogo Carlos Eduardo Valderrama (2009) en su artículo "La investigación en medios de comunicación en Colombia 1980-2009", expone un panorama general de la investigación y la reflexión desarrolladas en Colombia - durante los años 1980-2009 sobre los medios de comunicación. Reseña las principales tendencias de dichos trabajos, así como algunos aspectos de su producción esbozando preguntas críticas en torno a la producción del conocimiento sobre los medios de comunicación.

Refiere que muchas de estas investigaciones son producto de la conformación y desarrollo del campo de la comunicación y su respectiva institucionalización académica, relacionada además con la profesionalización del periodismo y la preocupación de la sociedad sobre el lugar preponderante que los medios de comunicación ocupan hoy en la vida cotidiana.

Al referirse a la década del 90, Valderrama (2009) enuncia que se efectúa una ruptura generalizada con la idea de la relación causal entre los medios y la audiencia. Se 
evidencia una relativa superación con la imagen de un sujeto inactivo ante los medios; y un progresivo acercamiento a la transdisciplinariedad e interdisciplinariedad de las investigaciones mediáticas. Expone además como en su contexto las investigaciones padecen un excesivo centralismo en cuanto a los lugares de publicación, así como el hecho de la falta de investigación y reflexión sobre los medios regionales y locales.

\section{Los mass media: en la mira}

Los medios han propiciado la creación de organizaciones e instituciones que los declaran como objeto de estudio; sistemas prácticos dirigidos a evaluar las producciones mediáticas, su gestión informativa y la relación con el público.

Es el caso de la Asociación para la Investigación de Medios de Comunicación (AIMC) organización empresarial española, sin ánimo de lucro que se encarga de la investigación, medición y control de audiencia de los diferentes medios de comunicación o publicidad a través de informaciones y estudios de carácter periódico. Constituida por un amplio grupo de empresas entre las que se destacan medios de comunicación (televisoras, emisoras de radio, periódicos, revistas, sitios de Internet) y entidades vinculadas al sector publicitario (anunciantes, agencias de publicidad, consultores), dedican su actividad al entorno comunicacional, tanto en su vertiente informativa como comercial.

Esta estructura ha demostrado la obtención de resultados eficaces en la mayor parte de los países desarrollados que cuentan con medios sólidos de comunicación, realizan estudios de auditorías de audiencia, investigaciones de medio-producto, esta última suministra información sobre el consumo de marcas y productos en relación con el público de los medios. Los sondeos se realizan en sectores concretos como la publicidad exterior, la radio, las televisoras locales o el cine.

La investigación que más relevancia le aporta es el Estudio General de Medio (EGM), sondeo multimedia de importante actualidad en España; es una vía certera de conocer los gustos y preferencias de los públicos, orientado, por supuesto a un componente publicitario. Mediante él se trata de conseguir información cuantitativa y cualitativa de las personas que están en contacto con los distintos medios y soportes. A partir de utilizar técnicas de sondeo se estudia por lo general la relación del sujeto con el uso y hábitos ante los medios de comunicación.

En América Latina, existen instituciones que se encargan de estudiar los medios, 
desde los más disímiles enfoques, tales como:

$\checkmark$ Consejo de Investigación de Medios (CIM), asociación civil mexicana que desde 1998 integra a representantes de agencias de medios, agencias de investigación, anunciantes y medios de comunicación interesados en la regulación de lãs prácticas, desarrollo y evolución de la investigación en medios, con el fin de promover consistencia en las metodologías de evaluación cuantitativa y cualitativa de las distintas plataformas de comunicación.

$\checkmark$ La Asociación Colombiana de Investigación de medios (ACIM), esta organización sin ánimo de lucro, se propone realizar investigación, medición y control de audiencia y comportamiento de los diferentes medios de comunicación o publicidad en Colombia a través de investigaciones y estudios de carácter periódico.

Sin dudas la investigación de los medios de comunicación es de vital importancia, pues es una forma de entender los procesos que se gestan a su interior y la repercusión que tienen para la audiencia.

\section{Observatorios de medios, una solución actual}

Entre las iniciativas que hoy sustentan la investigación de los mass media, podemos señalar los observatorios de medios, desplazados por Latinoamérica en países como Argentina, Guatemala, Bolivia, Perú, Ecuador, Colombia, México, Brasil iniciativa más longeva de América Latina- que se orientan hacia el monitoreo de los diarios, propiciar la discusión sobre los medios y desarrollar estudios de productos, procesos y procedimientos en los que intervengan los Medios de Comunicación.

Estas entidades promueven una observación crítica hacia los medios, delimitando si cumplen sus funciones, a través de la creación de escenarios de debates tanto públicos como académicos, caracterizados por un espíritu colaborador. Aunque centran su atención hacia la identificación, análisis y discusión de problemas de la comunicación en los procesos de emisión, circulación y recepción de la información, promueven espacios de encuentros para la interacción del público con los medios.

Según refiere Castellanos (2007), no existe una definición exacta, se habla de ellos como una experiencia, una metodología, una institución, un proyecto, un concepto sobre el que aún hay muchas cosas por definir. Precisa además que se presentan de 
manera indistinta como campo de investigación y como objeto de estudio, en el primer caso por tratarse de escenarios en los que la información mediática, la producción y recepción son sus objetos de estudio y en el segundo porque los observatorios pasan a estar bajo la lupa, convirtiéndose así en objetos de análisis.

Los observatorios de medios surgen unos adscritos a universidades, como proyectos que resultan de un conjunto de investigaciones que tiene como objeto de estudio los medios; otros nacen de la asociación de grupos privados o públicos con el fin de analizar y estudiar problemas relacionados con los Medios de Comunicación. De una manera u otra ambos demuestran el interés que existe por investigar el fenómeno de los mass media.

Cuba, no está exenta de la oleada de investigación que tiene como centro a los medios de comunicación. Si bien los observatorios no son un fenómeno generalizado, en el país, se cuenta con el Centro de Información para la Prensa (CIPRE), que se desempeña además como observatorio mediático. Fundado el 7 de febrero de 1987, como uno de los acuerdos del Quinto Congreso de la Unión de Periodistas de Cuba organización gremial que lo rectora - es un centro de información especializada, que se encarga de la Gestión de Información y del Conocimiento para el sistema de prensa cubano.

Con un alcance nacional, cuenta con una red automatizada de información que enlaza a los principales medios de prensa, lo que permite trabajar en el perfeccionamiento de la actividad documental e informativa del sector periodístico en todas sus vertientes, las artes gráficas y la comunicación en general. Utiliza técnicas y métodos muy avanzados para el procesamiento, almacenamiento y transmisión de la información. Es una entidad sin ánimos de lucro, con una amplia cobertura temática que cuenta con tres grupos de trabajo, dedicados a la Gestión de Información, el Desarrollo Tecnológico y el Grupo Editorial.

Su directora Livia Reyes Ramírez, refiriéndose a los resultados investigativos del centro ,expresó que tienen tres áreas de resultados claves, el nodo virtual de la prensa escrita cubana, todos los soportes tecnológicos, tráfico, canales, web y además desarrollo de software. También es un medio de prensa que cuenta con la primera revista digital del país y por tanto es una redacción virtual y observatorio de periodismo cubano (REYES RAMÍREZ apud MONTES DE OCA, 30 sept. 2015)

El observatorio si bien cumple su función de análisis de la prensa, es una 
entidad para la gestión de información y conocimiento como principio fundamental; a partir de ello, si ampliara su espectro de manera general y utilizara todos los mecanismos tecnológicos que posee, podría convertirse en una vía para la investigación de los medios en nuestro país.

\section{Metodología}

Como parte del sustento fáctico del presente estudio se procedió a la utilización de técnicas científicas, para la recolección, análisis y triangulación de la información de forma tal que desde una base fidedigna, se obtengan resultados de la realidad objetiva.

Se aplicaron como técnicas la entrevista, los grupos de discusión y la observación participante, para definir los criterios, condicionamientos, valoraciones y expectativas del personal de los medios que se ven implicados de manera directa o indirecta en las investigaciones sociales, para ello, se realizaron:

$\checkmark 4$ grupos de discusión: Emisoras CMKC Radio Revolución, CMKW Radio Mambí; Radio Baraguá y el telecentro provincial Tele Turquino, con el objetivo de compendiar criterios acerca de la importancia que le atribuyen desde su campo de acción a las investigaciones sociales; así como propiciar diversidad de criterios referentes al trabajo investigativo que se realiza. Participaron indistintamente tanto periodistas, directivos como realizadores de programas.

$\checkmark 20$ entrevistas: A directivos de los medios, investigadores sociales y personas que de una forma u otra se ven involucrados en el proceso de investigación.

$\checkmark$ Observación participante: En días indistintos, para definir las relaciones que se establecen alrededor de las dinámicas estructurales de investigación social y delimitar procedimientos esenciales que caracterizan el desarrollo de dichas investigaciones.

$\checkmark$ Revisión bibliográfica: Se utilizó para la compilación de información sobre los inicios de las investigaciones sociales en Santiago de Cuba, cotejada a su vez con criterios de personas que formaron parte de este sistema de investigación. Además se consultaron documentos que aportaron los principios organizativos necesarios para sustentar el diseño de la estructura, que se pretendía crear.

$\checkmark$ Matriz DAFO: Para el análisis de amenazas, debilidades, oportunidades y fortalezas a partir de realizar el diagnóstico del sistema de la radio y la televisión en Santiago de Cuba. 
Teniendo en cuenta que las técnicas utilizadas tributan en ocasiones a aspectos comunes, para una mayor comprensión de los resultados, se agruparon por temas, que se van articulando a todo lo largo de la investigación.

\section{Caracterización del Sistema de Investigaciones Sociales en Santiago de Cuba. Dinámica estructural}

El Sistema de Investigaciones Sociales en la Provincia de Santiago de Cuba se erige de manera independiente para la radio y la televisión. Aunque ambos responden al Instituto Cubano de Radio y Televisión (ICRT), cada uno posee características propias, lo que no es limitante, para que entre ellos existan puntos de convergencias.

El análisis del Sistema de Investigaciones Sociales en ambos médios, nos permiten señalar que anualmente se realizan mayor cantidad de investigaciones en la radio que en la televisión. La diferencia en la cantidad de estudios tiene como principal causa la disponibilidad de personal, en el caso de la radio a la hora de realizar una investigación de carácter provincial se convoca a todo el personal que atiende investigaciones sociales, el cual se apoya en ocasiones de otros especialistas del medio.

Las temáticas de las investigaciones están dirigidas al análisis de los públicos y consumo e impacto del mensaje, teniendo relevancia los estudios de hábitos de vida, gustos y preferencias; sondeos de audiencia; y estudios a la programación tanto informativa como variada, y a especialidades, como locución, música, sonido y guión de programas.

Los estudios están encaminados también a su auto-imagen, diagnóstico de la comunicación organizacional, relaciones que se establecen tanto con el público externo como el interno, para conocer opiniones y analizar las dinámicas organizacionales internas, que permitan establecer maneras armónicas y coordinadas de trabajo en equipo. El registro de investigaciones de la radio es más numeroso que el de la televisión, no solo porque el mecanismo de investigación social cuente con más tiempo, sino porque el sistema se encuentra también, mejor estructurado.

A través de criterios definidos por los directivos de los medios, implicados en el proceso de investigación social, se precisa, que el personal que ocupe este cargo debe realizar diversidad de funciones que permitan la realización de una efectiva investigación social, además de ser graduado de nivel superior en especialidades afines 
a la investigación comunicacional y tener conocimiento de la actividad, para la categoría de técnico: debe conocer el trabajo de investigación social y en ambas estar habilitado como tal.

\section{Investigaciones sociales: valoraciones y condicionamiento}

La aplicación de las técnicas - especialmente los grupos de discusión y la entrevista a los directivos de los medios, permitieron definir una serie de criterios referentes a la importancia que se le atribuye a las investigaciones sociales, así como valoraciones acerca del trabajo que se realiza, a partir de que constituyen la base científica para el trabajo, se convierten en el eje fundamental por el que se va a regir el diseño de la programación, teniendo en cuenta que los medios trabajan para un público y conocer los elementos que se componen en su interior garantiza mayores índices de audiencia.

Por otra parte, admiten el desarrollo de estudios puntuales que plasman las principales necesidades, inconformidades, sugerencias tanto del emisor como del receptor. Además, si la investigación cuenta con un diseño cuidadoso, con objetivos claros y bien definidos, se pueden obtener resultados que retribuyan a la calidad de la programación que estaría adecuada a los intereses reales y puntuales de su público, y que cumpliría con su cometido y objeto social, convirtiéndose en un medidor de calidad, una guía, un termómetro, que a partir de la caracterización de los modos de hacer, permiten delimitar los mecanismos que se deben modificar, transformar, fortalecer o consolidar a fin de que los medios estén a tono con las características y necesidades de la sociedad.

Al decir del Director Provincial de Radio, en Santiago de Cuba, las investigaciones sociales, no deben quedarse en la epidermis del asunto, constituyen puntos directivos para cualquier cambio o modificación que se pretenda realizar en la programación de los medios de comunicación; son la relación más directa entre el emisor y su receptor, agrega que las investigaciones son decisivas si de verdad se quiere hacer una programación con calidad que responda a los intereses para los cuales se crearon los medios, son decisivas si se utilizan adecuadamente

Si bien de manera general se podría definir que coexiste un clima de respeto y cordialidad, se evidenció, a través de las técnicas aplicadas, la necesidad de una mayor calidad, rigurosidad, profundización y sistematicidad en las investigaciones, insuficiencia de estudios desde diferentes ciencias (Psicología, Sociología, 
Comunicación, Antropología), que diversifiquen el diapasón de resultados, carencia de personal para realizar las investigaciones, necesidad de un equipo y recursos materiales.

A partir del análisis y en respuesta a las deficiencias encontradas en el Sistema de Investigaciones Sociales, se procedió a la modelación teórica de la estructura que a continuación se presenta.

\section{Equipo de Investigación Social para los Medios Masivos de Comunicación}

La modelación de una estructura organizativa para el Sistema de Investigaciones Sociales del Instituto Cubano de Radio y Televisión en Santiago de Cuba es la esencia de esta investigación, la cual toma como referencia la "Propuesta de Estructura Organizativa de la Dirección de Seguridad Integral" de la Universidad Simón Bolívar de Venezuela del año 2008, en la que se propone una vía para ordenar y mejorar el desempeño de esta dirección adscrita al Vicerrectorado Administrativo de la Universidad.

Vale señalar que de este modelo solo se utiliza el diseño de la estructura, atemperado a las características y fines de la organización que se pretende crear. Los elementos que aquí se proponen son variables, pueden estar sujetos a modificaciones, según se considere pertinente para la implementación de la estructura.

La estructura organizativa se compone de 3 fases, las que se van articulando de manera coherente a partir de:

\section{Fase I: Definición de la orientación}

\section{Misión}

El Equipo de Investigación Social para los Medios Masivos de Comunicación es una entidad que busca potenciar el desarrollo de la actividad investigativa en los medios de comunicación, con el propósito de crear la base científica, para la adecuada articulación de los comunicados mediáticos.

\section{Visión}

Cuenta con un personal calificado, que dirige su trabajo al estudio de los medios de comunicación, a partir de la interacción constante con el público, explorando en elementos que permitan la satisfacción de sus gustos, preferencias y necesidades. Se erige como un ente investigador, capaz de crear estrategias que permiten estrechar los 
lazos entre ambos extremos de la comunicación (emisor- receptor) y está ventajosamente posicionado entre entidades con análoga función en su ámbito.

\section{Objetivo general}

Monitorear el impacto de los Medios de Comunicación en Santiago de Cuba, en sus destinatarios, a través de estudios permanentes del público receptor, en busca de una caracterización que tribute al aumento de la calidad de los procesos de producción mediática.

\section{Objetivos específicos}

Realizar estudios a los procesos de recepción mediática, definiendo los factores psicosociales que intervienen en la interpretación de los mensajes transmitidos.

> Caracterizar las dinámicas productivas de los órganos de prensa de Santiago de Cuba, con el objetivo de definir elementos que puedan integrarlos en un sistema que trabaje de conjunto, para la satisfacción de las necesidades del público.

> Constituir la principal vía de retroalimentación en la provincia, a partir de la calidad de las investigaciones, y de la viabilidad de sus propuestas de cambio.

Fase 2: Diagnóstico funcional

Análisis interno (fortalezas y debilidades)

A partir del estudio del sistema de investigaciones existente podemos definir como:

\section{Fortalezas}

$>\mathrm{Se}$ reconoce la importancia que tienen las investigaciones sociales para los Medios de Comunicación.

$>$ El personal de investigaciones a pesar de no contar con todos los recursos materiales para la realización de los estudios, adopta medidas para ejecutar su trabajo.

$>$ Reconocimientos obtenidos por el Sistema de Investigaciones Sociales de la radio a nivel nacional.

\section{Debilidades}

Presencia de una estructura organizativa que hoy no es totalmente funcional 
para los fines de las investigaciones sociales.

> Ausencia de personal, lo que influye en la disminución del alcance que puedan tener las investigaciones y del público a tener en cuenta.

$>$ No todo el personal cuenta con los conocimientos y las habilidades necesarias para desempañar la tarea de investigador.

$>$ Ausencia de recursos técnicos, necesarios para la realización de los estudios.

\section{Análisis externo (oportunidades y amenazas)}

\section{Oportunidades}

Las investigaciones sociales constituyen hoy la principal vía de retroalimentación para los Medios de Comunicación.

C Creciente interés de los directivos del medio por el tema de las investigaciones sociales.

Los investigadores se encuentran en estrecha vinculación con los receptores, lo que les permite ganar en niveles de aceptación y conocimiento del público potencial.

\section{Amenazas}

Poca vinculación del personal que labora en los medios a las investigaciones.

Si las investigaciones no se realizan con la calidad requerida, los medios nunca serán el reflejo de su público.

\section{Fase 3: Diseño y plan de implantación}

\section{Formulación de estrategias}

Al cruzar el análisis interno (fortalezas y debilidades) con el externo (oportunidades y amenazas) se define el camino a seguir mediante la propuesta de las siguientes estrategias:

$>$ Reestructurar el mecanismo de investigaciones sociales, de forma tal que exista un desempeño más eficiente de sus funciones y que responda a las verdaderas necesidades de los medios de comunicación de la provincia Santiago de Cuba.

Diseñar una estructura flexible capaz de enfrentar situaciones tanto internas como externas que puedan contribuir al alcance de sus objetivos. Estructura que sería capaz de adaptarse a las necesidades y cambios constantes que vive la 
sociedad y el país.

$>$ Incrementar la superación del personal de investigaciones sociales, a través de talleres, cursos, para que estén en sintonía con las teorías y metodologías más recientes en el aspecto investigativo.

$>$ Facilitar el encuentro entre investigadores sociales, con el objetivo de intercambiar conocimientos y unificar fuerzas y criterios.

$>$ Promover la cultura investigativa en el personal que labora en los medios de comunicación, para que exista mayor sensibilidad e inclusión en las investigaciones.

> Mantener las fortalezas y ejecutar planes que las consoliden, para perfeccionar el funcionamiento del sistema y ganar prestigio y reconocimiento a todos los niveles.

> Potenciar el trabajo con los receptores e ir más allá de la transferencia de información, buscar una participación comprometida en los procesos de producción mediática.

Paradigma de la reestructuración organizacional. Identificación de los procesos

El Equipo de Investigación Social para los Medios Masivos de Comunicación, a partir de la articulación de sus mecanismos, mantendrá un monitoreo constante sobre el trabajo de los medios, funcionando como "Observatorio mediático", a fin de guiar el rumbo de los órganos de prensa, hacia la consecución de su verdadero objeto social.

Los medios podrán solicitar investigaciones sociales según sus intereses, tanto el personal que los dirige, como editores, asesores, guionistas, directores de programas, periodistas u otra persona interesada en delimitar cuestiones relacionadas con el público interno y externo o impacto del mensaje.

El equipo también llevara a cabo proyectos de su autoría, según lo considere pertinente, orientados principalmente al desarrollo y perfeccionamiento de los medios de comunicación, además de prestar servicios integrales - relacionados con la comunicación - a otros centros que así lo soliciten, con el objetivo de mostrar sus estándares de calidad y eficiencia e instituirse como un centro de referencia.

Las entidades que soliciten las investigaciones serán las encargadas de financiar y propiciar los recursos materiales para el adecuado desempeño de las mismas, mientras el equipo se responsabiliza con la gestión del conocimiento y la presentación de los 
resultados en el tiempo establecido por ambas partes, con la realización de informes de todas las etapas del proceso de investigación, dígase desde la presentación del proyecto hasta la discusión y validación de los resultados.

El servicio prestado cuenta con un valor agregado:

Permitir la vinculación activa y directa del personal de los medios, interesados en relacionarse con la actividad investigativa, así como su colaboración - si así lo desea -, en la investigación que se esté realizando, mientras se respete lo establecido por el equipo.

Propiciar la capacitación a trabajadores de entidades no pertenecientes a los medios de comunicación que estén interesados en recibir o profundizar conocimientos referentes al diseño e implementación de investigaciones.

Constituye un espacio para la consolidación de las habilidades adquiridas durante el proceso de formación de estudiantes de carreras afines a la comunicación e investigación de público (Psicología, Sociología, Periodismo, Comunicación Social), así como para la superación de estos profesionales.

El funcionamiento del equipo estará encaminado sobre la base de procesos medulares y la respectiva interdependencia entres ellos.

\section{Imagen 1 - Diagrama de procesos}
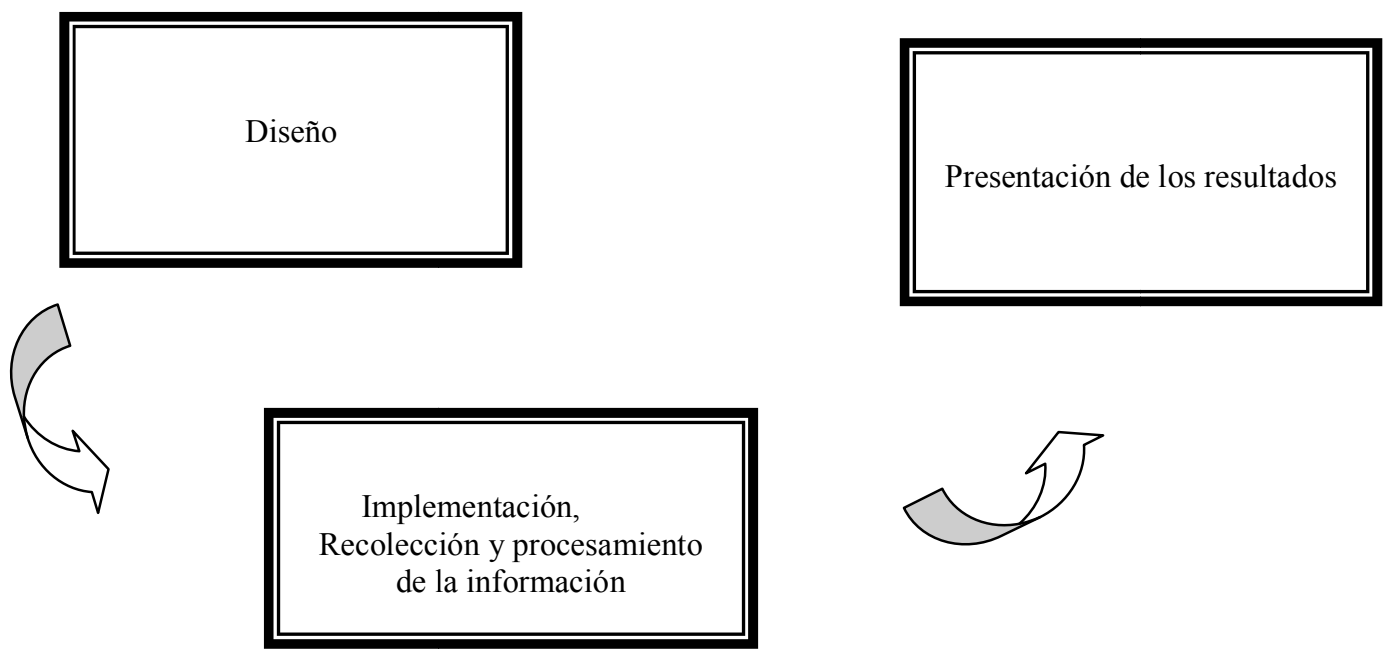


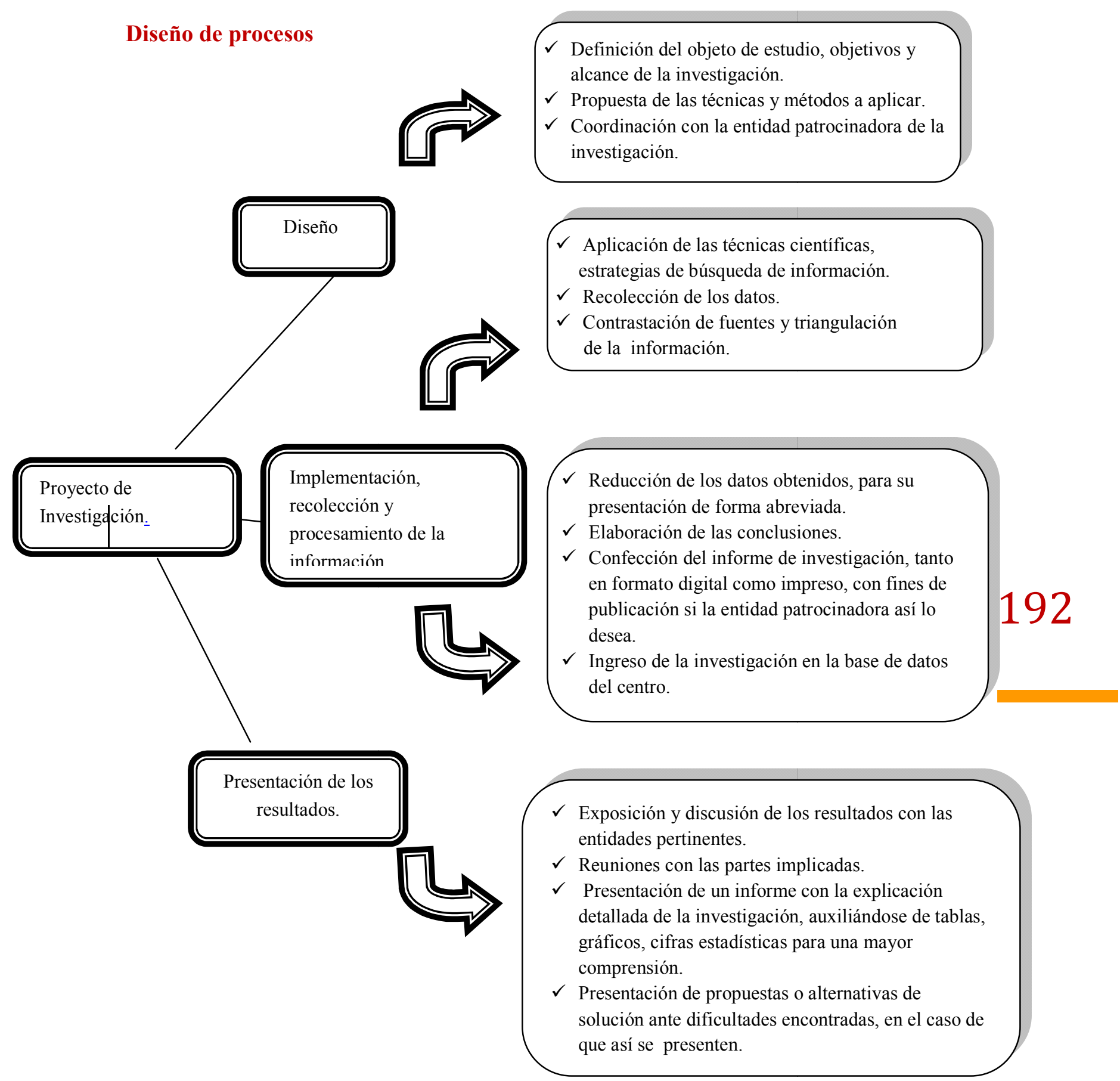

Fuente: Propuesta de Estructura Organizativa de la Dirección de Seguridad Integral" de la Universidad Simón Bolívar de Venezuela del año 2008.

\section{Diseño de la estructura organizativa}

El equipo a partir de un análisis detallado de sus características, objetivos y funciones, teniendo en cuenta las propuestas de los entrevistados debatidas en los 
grupos de discusión, estará compuesta por: Periodista, Psicólogo, Sociólogo, Comunicador Social, Estadístico, Especialista en Ciencias de la Información, además de staff de apoyo: Red de encuestadores (colaboradores externos).

Imagen 2 - Organigrama de funcionamiento del equipo de investigaciones sociales

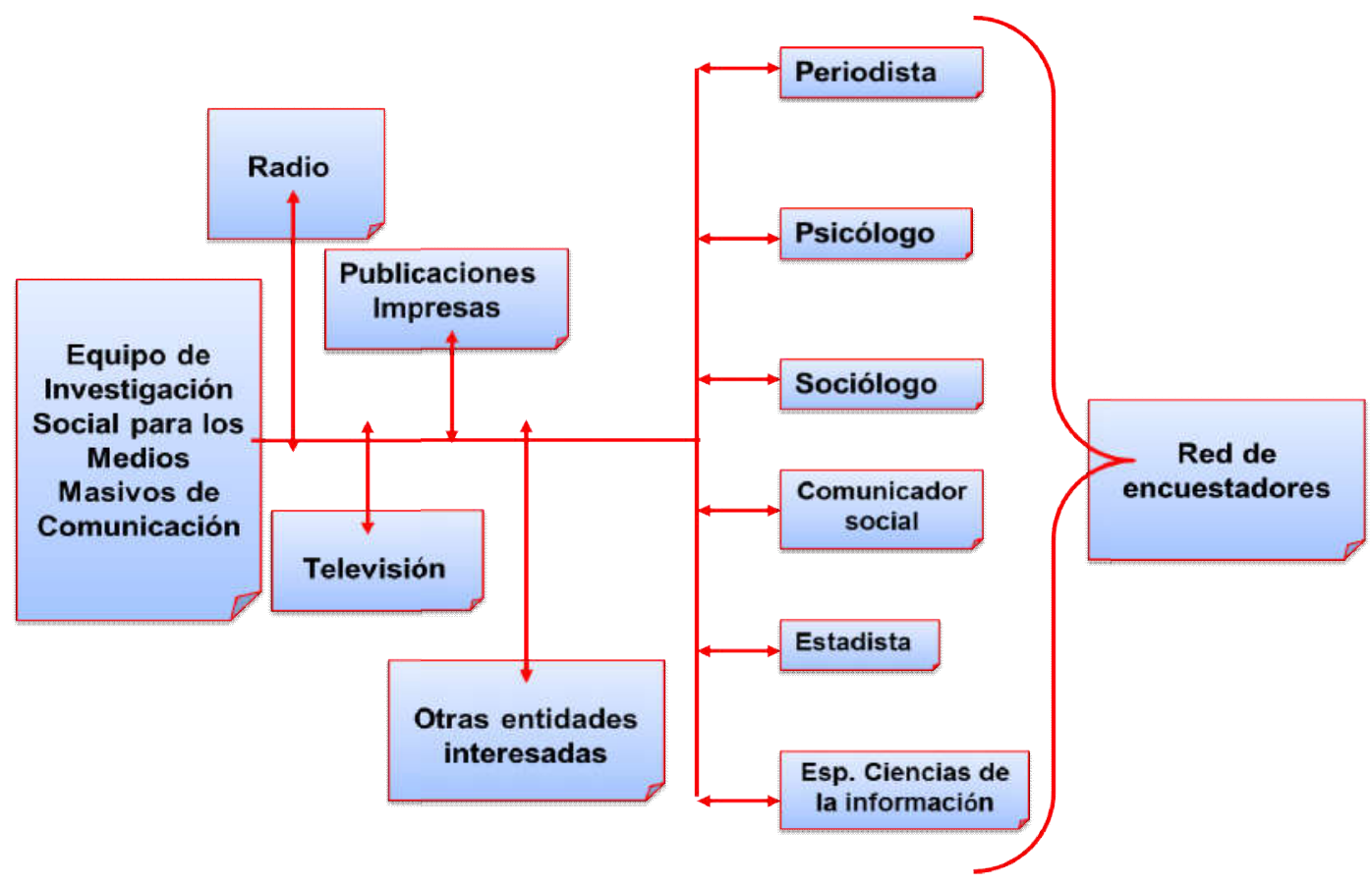

\section{Plan de implantación}

El período de implantación del proyecto sería de seis meses hasta un año y medio, siguiendo pasos lógicos con tiempos variables, involucrando a los decisores de los medios y especialistas.

\section{Conclusiones}

Los resultados de la investigación nos permiten concluir que la estructura propuesta potenciaría el desarrollo de la actividad investigativa, creando la base científica que sustentaría la producción mediática, a partir de la optimización de recursos basados en una estrategia de trabajo sólida y en la capacidad del personal que la integra. Además la implementación de este equipo de investigación dotaría a las publicaciones impresas de un medio para analizar a sus receptores, por otra parte, con esta estructura, se integraría el lenguaje investigativo de los medios, a fin de definir 
elementos que puedan constituir un sistema que trabaje de conjunto, para la satisfacción de las necesidades de sus destinatários. El Equipo de Investigaciones propuesto sería la base del futuro Observatorio de Medios en la provincia de Santiago de Cuba.

Debemos agregar que el sistema de investigaciones sociales se encuentra mejor estructurado en la radio que en la televisión, no obstante en ambos medios de comunicación existen deficiencias que conllevan al redimensionamiento de su estructura y métodos de trabajo. En ambos medios, las investigaciones están basadas en el análisis tanto cualitativos como cuantitativos que permiten evaluar la programación, a fin de mantener la calidad de los espacios; adecuar los horarios pertinentes según el sector de la población al que va dirigido y facilitar una mayor interacción entre la audiencia y el medio.

A pesar de que se reconoce la importancia de las investigaciones sociales, hay un distanciamiento con el personal que desempeña esas funciones en esos medios. Consideramos, además, la necesidad de realizar posteriores investigaciones que den continuidad a este estudio y señalen el camino hacia una verdadera optimización del Sistema de Investigaciones Sociales en la provincia de Santiago de Cuba, profundizando principalmente en los mecanismos que median su funcionamiento.

Submetido em: 21.03.2016

Aceito em: 09.02.2017

\section{REFERÊNCIA BIBLIOGRÁFICA}

ASOCIACIÓN PARA LA INVESTIGACIÓN DE MEDIOS DE COMUNICACIÓN (s/f): página oficial. Misión. Disponible en: <www.aimc.es/Que-es-la-aimc.html>. Consultado en: enero 2014.

CASTELLANOS, Juliana. (2007). Los observatorios de medios: bastiones de la investigación mediática. Razón y Palabra. Primera Revista Electrónica en América Latina Especializada en Comunicación, Quito, Ecuador, n. 73, agosto/oct. 2010. Disponible en: $<$ http://www.razonypalabra.org.mx/N/N73/Varia73/23Castellanos_V73.pdf $>$. Consultado en:

CHRISTOFOLETTI, Rogério. Observatorio de Medios: un caso brasileño. Revista Latinoamericana de Comunicación Chasqui. Centro Internacional de Estudios Superiores de Comunicación para América Latina, Quito, Ecuador, n. 95, p. 40-45, sept. 2006.2 Disponible en: $<$ chasqui.ciespal.org/index.php/chasqui/article/download/1586/1609>. Consultado em: 
marzo 2014.

DELGADO, Yaiset. De los medios a los públicos en busca del eslabón perdido: Pertinencia de la organización científica de los dispositivos de retroalimentación en el sistema de órganos de prensa en Guantánamo. 2013. (Tesis impresa de licenciatura em Periodismo). Universidad de Oriente, Cuba.

DUARTE, Gustavo Adolfo León. Sobre la institucionalización del campo académico de la comunicación en América Latina. Una aproximación a las características estructurales de la investigación latinoamericana en comunicación. (Tesis inédita Doctoral), Departament de Periodisme i de Ciències de la Comunicació. Universidad Autónoma de Barcelona, Barcelona, 2006. Disponible en marzo 2014 $<$ http://www.tdx.cat/bitstream/handle/10803/4196/gald1de1.pdf;jsessionid=7B9266D47 AC97E0EB7AA74354C4263FC? sequence=1>. Consultado en: marzo 2014.

GONZÁLEZ, Yisel. Sistema de Investigación del ICRT: una mirada en el tiempo. 2012. (Tesis impresa de licenciatura en Periodismo). Universidad de Oriente, Cuba.

ICRT. Manual metodológico de la investigación social en la radio y la televisión. 2012.

INFORME ejecutivo. Propuesta de Estructura Organizativa de la Dirección de Seguridad Integral de la Universidad Simón Bolívar de Venezuela. 2008.

LICENCIATURA en RR.HH. Universidad de Champagnat. La estructura organizacional. 2002. Disponible en: <www.gestiopolis.com/la-estructuraorganizacional/>. Consultado en: mayo 2015.

MONTES DE OCA, Lucia. Continúan los debates en Simposio Internacional de Comunicación Social: Entrevista a Livia Reyes Ramírez. Periódico Sierra Maestra, 2015. Disponible en: <www.sierramestra.cu/santiago/ciencia/44430-continuanlos/debate-en-el-simposio-intenacional-de-comunicación social $>$. Consultado en: marzo 2015 .

PARTIDO COMUNISTA DE CUBA. Primera Conferencia Nacional del Partido Comunista de Cuba. Documento Base. La Habana: Editora Política. 2012.

REYES RAMÍREZ, Livia. Observatorio Cubano de Periodismo. Grupo Gestión de Información y del Conocimiento. Centro de Información para la Prensa. ACIMED. v. 15, n. 6, 2007. Disponible en: <http://eprints.rclis.org/10217/1/acimed-15-6-2.pdf >. Consultado en: mayo 2015.

SAMPIERI, Roberto Hernández; COLLADO, Carlos Fernández; LUCIO, Pilar Baptista. Metodología de la investigación. Cuarta edición. México: McGraw-Hill, Interamericana Editores S.A., 2006. Disponible en: $<$ https://competenciashg.files.wordpress.com/2012/10/sampieri-et-al-metodologia-dela-investigacion-4ta-edicion-sampieri-2006_ocr.pdf>. Consultado en: mayo 2015.

UNIVERSIDAD CARLOS III DE MADRID. Doctorado en Investigación en Medios de Comunicación. Formación. [s.f.]. Disponible en: <www.portal.uc3.m.es/postgrado_maes_doct/doctorado>. Consultado en: 5 marzo 2015. 
VALDERRAMA, Carlos Eduardo. La investigación en medios de comunicación en Colombia (1980-2009) o Mass Media Social Research in Colombia (1980-2009). Revista Nómadas, Bogotá, n. 31, jul./dic. 2009. Disponible em: $<$ http://www.scielo.org.co/scielo.php?script=sci_arttext\&pid=S0121$75502009000200018>$. Consultado en: mayo 2015.

WIMMER, Roger; DOMINICK, Joseph. Introducción a la investigación de medios masivos de comunicación. México: Thomson Editores, 2007. [Libro en línea]. 